University of Nebraska - Lincoln DigitalCommons@University of Nebraska - Lincoln

9-2017

\title{
Experimental-Statistical Investigation of Testing Variables of a Semicircular Bending (SCB) Fracture Test Repeatability for Bituminous Mixtures
}

G. Nsengiyumva

University of Nebraska - Lincoln

T. You

University of Nebraska - Lincoln

Yong-Rak Kim

University of Nebraska - Lincoln, yong-rak.kim@unl.edu

Follow this and additional works at: https://digitalcommons.unl.edu/civilengfacpub

Nsengiyumva, G.; You, T.; and Kim, Yong-Rak, "Experimental-Statistical Investigation of Testing Variables of a Semicircular Bending (SCB) Fracture Test Repeatability for Bituminous Mixtures" (2017). Civil Engineering Faculty Publications. 80.

https://digitalcommons.unl.edu/civilengfacpub/80 
Manuscript received February 29, 2016; accepted for publication July 19, 2016; published online October 25, 2016.

${ }^{1}$ Dept. of Civil Engineering, 362D Whittier Research Center, Univ. of Nebraska, Lincoln, NE 68583

2 Dept. of Civil Engineering, $362 \mathrm{H}$ Whittier Research Center, Univ. of Nebraska, Lincoln, NE 68583

3 Dept. of Civil Engineering, 362N Whittier Research Center, University of Nebraska, Lincoln, Nebraska 68583 (Corresponding author), e-mail: ykim3@unl.edu
G. Nsengiyumva, ${ }^{1}$ T. You, ${ }^{2}$ and Y.-R. Kim ${ }^{3}$

\section{Experimental-Statistical Investigation of Testing Variables of a Semicircular Bending (SCB) Fracture Test Repeatability for Bituminous Mixtures}

\section{Reference}

Nsengiyumva, G., You, T., and Kim, Y.-R., "Experimental-Statistical Investigation of Testing Variables of a Semicircular Bending (SCB) Fracture Test Repeatability for Bituminous Mixtures," Journal of Testing and Evaluation, Vol. 45, No. 5, 2017, pp. 1691-1701, http://dx.doi.org/10.1520/JTE20160103. ISSN 0090-3973

\section{ABSTRACT}

Given the fact that fracture is a primary distress causing pavement failure, it is important to identify and characterize the fracture/cracking properties of asphalt concrete mixtures and to include them in pavement design processes. This study examined the testing variables for a reliable and practical semicircular bending (SCB) fracture test to evaluate the fracture characteristics of asphalt concrete mixtures at intermediate service temperatures. An integrated experimental-statistical approach was employed to identify testing variables by which repeatable SCB test results can be achieved. Using a typical Nebraska asphalt mixture, five critical testing variables (i.e., the number of testing specimens, specimen thickness, notch length, loading rate, and testing temperature) of the SCB test were investigated due to their significant effects on mixture fracture characteristics. Statistical analysis of test results indicated that approximately six specimens/replicates were a reasonable sample size that could properly represent asphalt concrete fracture behavior of a typical dense-graded mixture. Then, the coefficient of variation (COV) of the mixture fracture energy for six specimens was used to evaluate the effects of other remaining test variables. A range of a specimen thickness of 40 to $60 \mathrm{~mm}$, a notch length from 5 to $40 \mathrm{~mm}$, and a testing temperature between 15 and $40^{\circ} \mathrm{C}$ showed the reasonably low COV value of fracture energy at around or less than $10 \%$. The loading rates ( 0.1 to $10 \mathrm{~mm} / \mathrm{min}$.) attempted in this study did not show any significant differences in the testing repeatability.

\section{Keywords}

semicircular bending test, bituminous mixture, fracture energy, statistical analysis 


\section{Introduction}

Fracture in asphalt concrete pavements is directly related to various types of functional and structural distresses including fatigue (both top-down and bottom-up) cracking, reflective cracking, and transverse (thermal) cracking. Consequently, the service life and reliability of the asphalt concrete pavements are critically reduced as results of these cracks. In the effort of characterizing fracture properties of asphalt concrete mixtures and concurrently improving the mechanical and structural performance of asphalt concrete pavement, various fracture testing methods such as the single-edge notched beam (SEB) test [1] and the disk-shaped compact tension (DCT) test [1,2] have been attempted. As shown in Fig. 1a, the SEB test involves a three-point bending of a notched asphalt concrete beam specimen, but is impaired by a complex specimen fabrication that requires significant testing efforts. This test is also not appropriate for field cores that are usually circular disks. Although the DCT test (Fig. 1b) has a circular geometry with loading holes to maximize the potential fracture area and consequently reduce geometry-associated error, there is a possibility of stress concentration at the loading holes. Moreover, specimen fabrication and preparation of the DCT test is not simple due to accessories required to position the specimen in the testing mount to induce pure opening mode fracture.

Because of the issues of the aforementioned fracture tests, a semicircular bending (SCB) test (Fig. 1c) has been attractive in the asphalt concrete pavement community [3-11] for its several advantages: (1) easiness and effectiveness in fabricating specimens, (2) suitability for field cores, and (3) repeatability in testing results $[3,4,6,12,13]$. Although a specimen for the SCB test has a lower fracture ligament area compared to that of the DCT test, the semicircular geometry enables one to test twice as many specimens obtained from field cores or laboratorycompacted samples. In addition, the SCB has shown great potential for characterizing mixed-mode fracture behavior of asphalt concrete mixtures by simply adjusting an inclination angle of the notch and the space between two supports [3,14]. It should be noted that only pure opening mode (as shown in Fig. 1c) will be investigated in this study.
Initially, the SCB test method was proposed by Chong and Kuruppu [15] because other existing fracture tests based on linear elastic fracture mechanics were expensive and difficult to perform for rock materials. Later, the SCB test was adopted in the asphalt community and proven to be adequate in evaluating fracture properties of both laboratory compacted samples and field cores due to its simplified specimen preparation [16]. SCB test in asphalt concrete can either be conducted at low temperatures (from -30 to $-10^{\circ} \mathrm{C}$ ) to evaluate thermal cracking potential of mixtures $[5,11,17-20]$ or at intermediate temperatures (from 21 to $25^{\circ} \mathrm{C}$ ) to characterize fatigue cracking $[3,4,12,21,22]$. SCB testing at the intermediate temperature has become increasingly attractive $[13,21]$ to simply characterize fatigue cracking potential of mixtures instead of performing time-taking fatigue tests with many repeated loading cycles. However, despite showing sensitivities to testing variables such as loading rate, specimen thickness, and testing temperature $[6,12,23]$, SCB test has not been fully investigated in the selection of testing variables that can provide statistically representative fracture characteristics of asphalt mixtures.

Several studies $[6,7,24]$ have performed SCB tests with testing variables selected somewhat randomly based on previous experiences [2,25], which typically leads to inconsistent and nonrepeatable test results. In addition, it is not clear how many SCB specimens should be tested in order to reasonably examine the fracture behavior of an asphalt concrete mixture. Obviously, with a certain set of testing variables, SCB test would yield results with a reasonably sufficient level of repeatability. Thus, there is a need to explore the SCB test with an appropriate set of testing variables that ensure the testing repeatability and reliability to evaluate the fracture characteristics of typical asphalt concrete mixtures.

\section{Study Objectives}

The primary goal of this study is to investigate SCB testing variables so that the SCB test can be used in the form of a reliable-repeatable test method, particularly to evaluate the cracking resistance of typical asphalt concrete mixtures. In order to achieve the goal, a systematic testing efforts and statistical analyses are integrated to investigate core testing variables

\section{FIG. 1}

Fracture tests for asphalt concrete mixtures: (a) singleedge notched beam (SEB), (b) disk-shaped compact tension (DCT), and (c) semicircular bending (SCB) test.

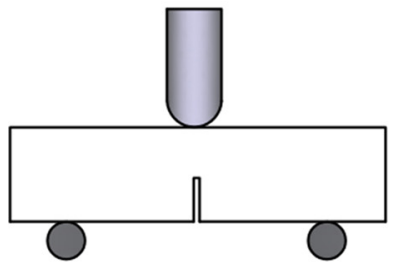

(a)

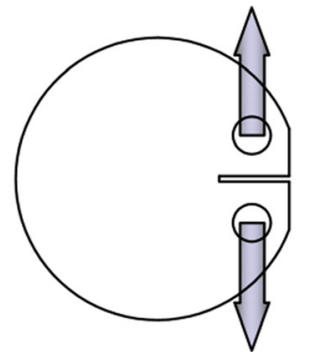

(b)

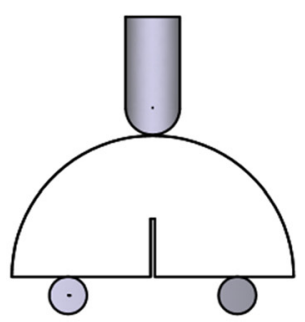

(c) 
FIG. 2

Research methodology used in this study.

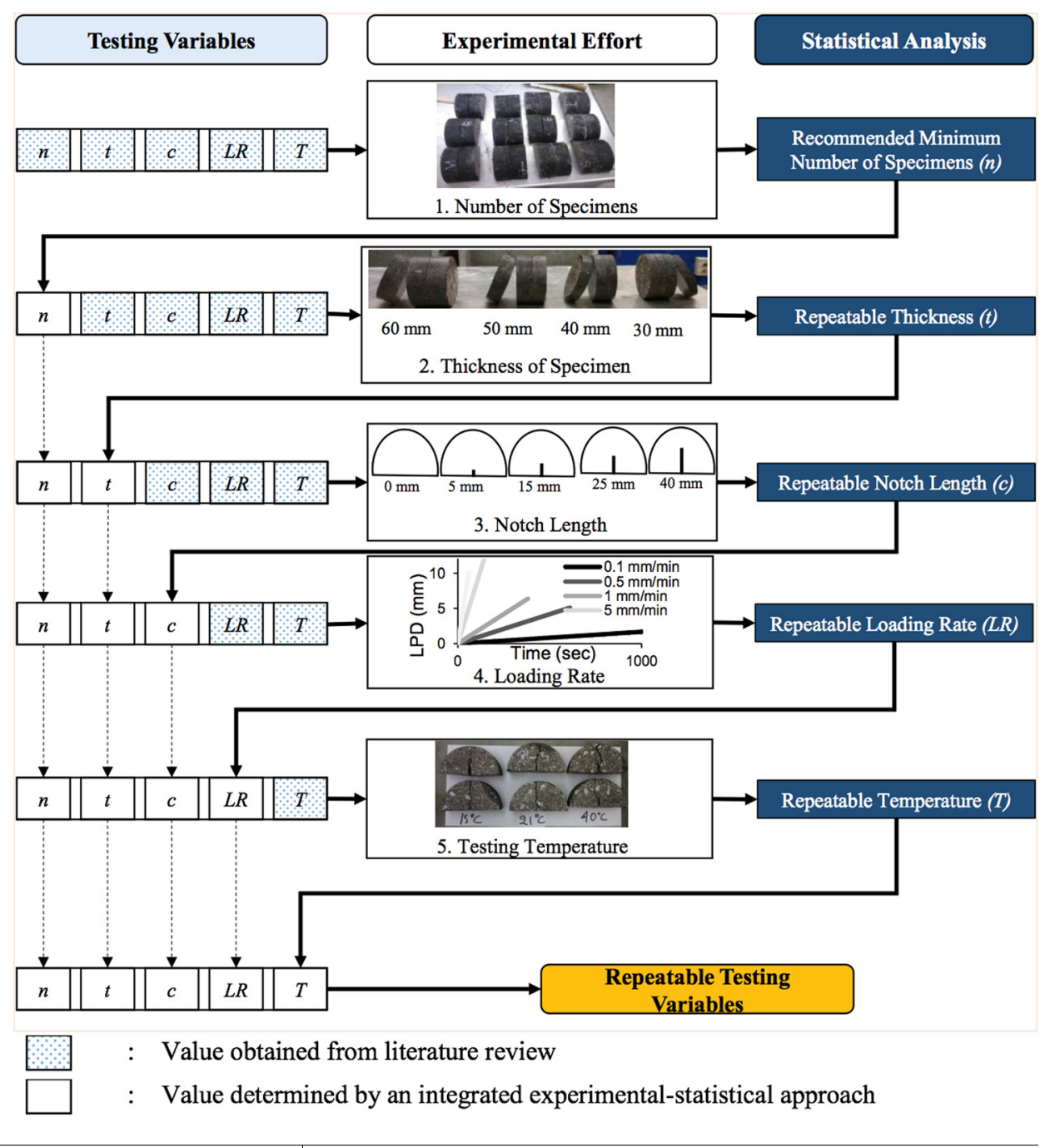

First of all, in order to determine the recommended minimum number of specimens, an extensive literature review was conducted so that a reasonable trial set of testing variables can be applied to a group of SCB specimens. Using the trial set of testing variables, a total of 18 SCB specimens were tested in this study and its statistical analyses were conducted to find the required number of SCB specimens at a desired confidence level and a margin of error. With the minimum number of specimens determined, the effects of the four remaining critical testing variables (i.e., specimen thickness, notch length, loading rate, and testing temperature) were then explored by varying one variable at a time while others remained constant. This allows for the isolation and characterization of the effect of each variable on the test results. The consistency in test results was evaluated by the coefficient of variation (COV), which is defined as the standard deviation divided by the mean [26], of fracture energy. This integrated experimental-statistical approach would lead to a recommended combination of the SCB testing variables to characterize the cracking resistance of asphalt concrete mixtures at intermediate service temperature conditions. 
FIG. 3

Fracture energy $\left(G_{f}\right)$ calculation: (a) fracture work $\left(W_{0}\right)$ and (b) ligament length (a) based on actual crack path.

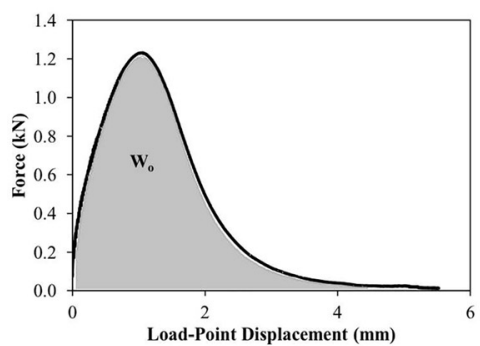

(a)

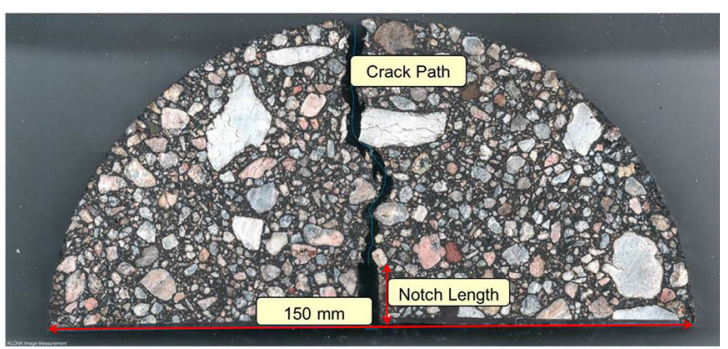

(b)

\section{Fracture Energy}

In this study, fracture energy $\left(G_{f}\right)$ was chosen as a fracture indicator for asphalt concrete mixtures. Generally, it is attractive for simply evaluating the fracture characteristics of asphalt concrete mixtures that are highly heterogeneous and nonlinear inelastic compared with other fracture properties, such as the J-integral $\left(J_{c}\right)[2,27,28]$. Because $J_{c}$ quantifies the rate of change in strain energy to the change of notch length [13], it requires multiple notch lengths, which might be a source of greater variations in test results in a highly heterogeneous material such as asphalt concrete. The fracture energy is calculated by [29]:

$$
G_{f}=\frac{W_{o}+m g \delta_{o}}{A_{\text {lig }}}
$$

where:

$W_{o}=$ fracture work, the area below the load-displacement curve, as shown in Fig. 3a,

$m=$ a mass,

$g=$ the gravitational acceleration,

$\delta_{o}=$ deformation, and
$A_{\text {lig }}=$ the ligament area and can be calculated by multiplying the crack path (Fig. 3b) with the specimen thickness. It can be noted that the mass $(m)$ of the specimen is negligible in Eq 1 as small specimens are typically used, which infers insignificant effects of specimen mass on the total fracture energy.

\section{Materials}

In this study, a typical Nebraska asphalt concrete mixture (i.e., $\mathrm{SPH}$ ) was used to prepare SCB specimens for laboratory tests. Loose mixtures were collected during construction and transported to the laboratory in sealed containers to prevent aging by oxidation. This mixture is widely used in Nebraska highways with high traffic-flow rates. It consists of $35 \%$ recycled asphalt pavement (RAP) and PG 64-34 binder with a warm mix asphalt additive. Proportionally, $5.20 \%$ of the binder content in the total weight of the mixture and $0.7 \%$ of the warm mix additive in the weight of the binder were mixed, along with a blend of aggregates from four sources with a nominal maximum aggregate size of $12.5 \mathrm{~mm}$. Table 1 presents aggregate gradations from four different sources, a combined gradation after blending, and geometric aggregate properties of the combined blend.

TABLE 1 Aggregate gradation and consensus properties.

\begin{tabular}{|c|c|c|c|c|c|c|c|c|c|c|}
\hline \multirow[b]{2}{*}{ Materials } & \multirow[b]{2}{*}{$\%$} & \multicolumn{9}{|c|}{ Sieve Analysis (Wash) } \\
\hline & & $3 / 4 "$ & $1 / 2 "$ & $3 / 8^{\prime \prime}$ & $\# 4$ & $\# 8$ & $\# 16$ & $\# 30$ & $\# 50$ & $\# 200$ \\
\hline 3/4" Clean & 10 & 100.0 & 60.0 & 18.0 & 2.0 & 2.0 & 1.0 & 1.0 & 1.0 & 1.0 \\
\hline Crushed Gravel & 50 & 100.0 & 100.0 & 100.0 & 92.7 & 73.0 & 45.2 & 29.1 & 16.2 & 6.3 \\
\hline 2A Gravel & 5 & 100.0 & 95.4 & 90.9 & 68.0 & 27.3 & 8.6 & 3.5 & 1.1 & 0.2 \\
\hline Millings (RAP) & 35 & 100.0 & 94.2 & 93.2 & 85.1 & 52.3 & 38.4 & 25.1 & 19.8 & 7.8 \\
\hline Combined Gradation & & 100.0 & 93.7 & 89.0 & 79.7 & 56.4 & 36.6 & 23.6 & 15.2 & 6.0 \\
\hline \multirow[t]{2}{*}{ Specification Range } & & - & 90 & - & - & 28 & - & - & - & 2 \\
\hline & & 100 & 100 & $<90$ & - & 58 & - & - & - & 10 \\
\hline \multicolumn{11}{|c|}{ Consensus Properties } \\
\hline FAA & CAA & & SE & & $\mathrm{F} \& \mathrm{E}$ & & & & & Design $\mathrm{G}_{\mathrm{sb}}$ \\
\hline 45 & 99/96 & & 79 & & 0.1 & & & & & 2.585 \\
\hline
\end{tabular}

NOTE: $\mathrm{FAA}=$ fine aggregates angularity; $\mathrm{CAA}=$ coarse aggregates angularity; $\mathrm{SE}=$ sand equivalent; $\mathrm{F} \& \mathrm{E}=$ flat and elongated particles; $\mathrm{D} / \mathrm{B}=$ dust-to-binder ratio; $\mathrm{G}_{\mathrm{sb}}=$ bulk specific gravity; “-” = not specified. 
FIG. 4

SCB specimen fabrication process: (a) compacting, (b) slicing, and (C) notching.

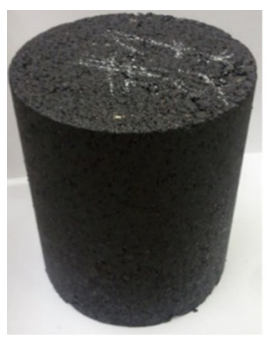

(a)

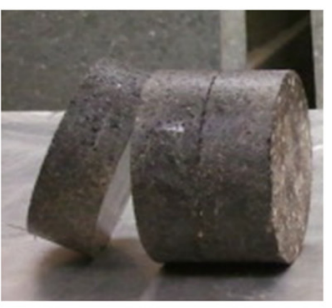

(b)

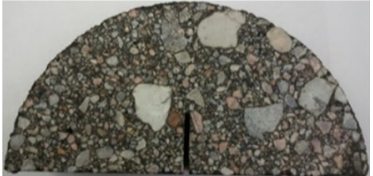

(c)

\section{SPECIMEN FABRICATION AND TESTS}

Prior to testing, the asphalt concrete loose mixture was reheated for two hours at $160^{\circ} \mathrm{C}$. The reheating serves to satisfy the required compaction temperature of mixtures to fabricate samples. A Superpave gyratory compactor was then used to produce tall compacted samples of $150 \mathrm{~mm}$ in diameter and $170 \mathrm{~mm}$ in height (Fig. 4a), with target air voids of $4 \pm 0.5 \%$. Multiple slices with desired thicknesses, ranging from 25 to $60 \mathrm{~mm}$ in this study, were then prepared after removing the top and bottom parts from the tall compacted samples, (Fig. 4b). Each slice was then cut into halves to yield two SCB specimens with a desired notch (Fig. 4c). It is noted that the introduced notch serves as a crack initiator because this test aims solely to characterize the fracture properties of asphalt concrete mixtures during crack propagation rather than crack initiation [30]. Special care was taken in producing the initial notch because the geometry and the quality of the notch tip may significantly affect the fracture behaviors of SCB specimens.

All mechanical tests in this study were performed using the Universal Testing Machine-25 kN (UTM-25) with an environmental chamber for temperature control. All specimens

FIG. 5 Test setup for semicircular bending (SCB) specimen with a notch.

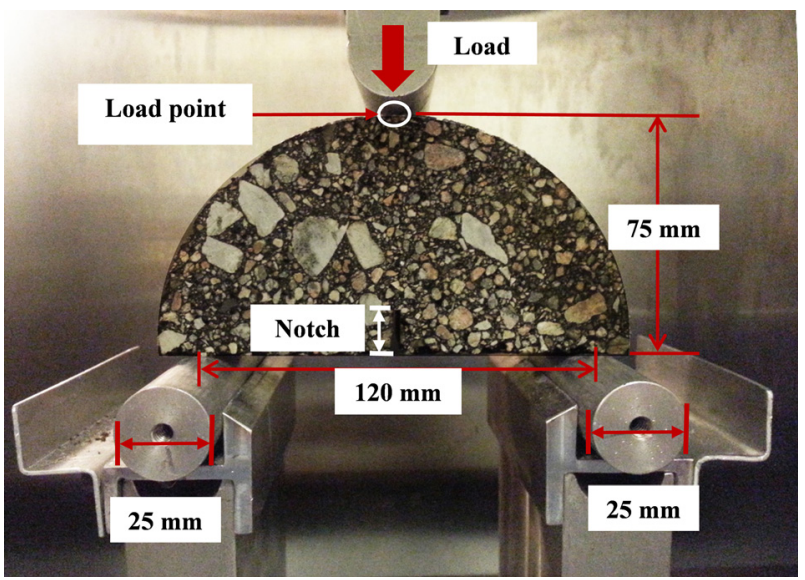

were allowed a minimum of $4 \mathrm{~h}$ inside the chamber to reach temperature equilibrium prior to testing. For accuracy, the temperature was read from a thermometer embedded in a dummy sample that was placed inside the environmental chamber. Each specimen was roller-supported on a test fixture with a span of $120 \mathrm{~mm}$ (see Fig. 5). It is noted that lubrication was applied at the supports to mitigate friction and that a positioning tool was used to avoid eccentric loads. Subsequently, a monotonic displacement rate was applied to the top center line of the specimens. A data acquisition system simultaneously monitored the reaction force and the loading point displacement during testing. It is noted that a machine compliance issue can result from the use of the equipment displacement transducer. This could be appropriately resolved by controlling the notch-mouth opening displacement (NMOD) in the test, which is in progress by the authors.

\section{Test Results and Discussion}

\section{THE NUMBER OF SPECIMENS $(\boldsymbol{n})$}

The number of specimens (sample size) of an experimental test is very critical in that a too large sample size may waste time and resources, while a too small sample size may lead to inaccurate results. Therefore, determining the recommended minimum number of specimens for a test method is a significant task for obtaining reliable outcomes with sound repeatability and efficiency. Consequently, the first effort for the SCB test development was to statistically investigate the relationship between the sample size and the variation of the results. Typically, for sample size less than 30 and population variance is unknown, the required sample size can be calculated by [26]:

$$
t_{\alpha / 2, d f}=\frac{\bar{y}-\mu}{s / \sqrt{n}} \Rightarrow n=\left[\frac{t_{\alpha / 2, d f} \times s}{E}\right]^{2}
$$

where:

$n=$ the number of specimens,

$t_{\alpha / 2, d f}=$ the student $t$-distribution with a given probability level $(\alpha)$ and degree of freedom $(d f)$, 
TABLE 2 Example of standard deviation estimation (with 5 specimens)

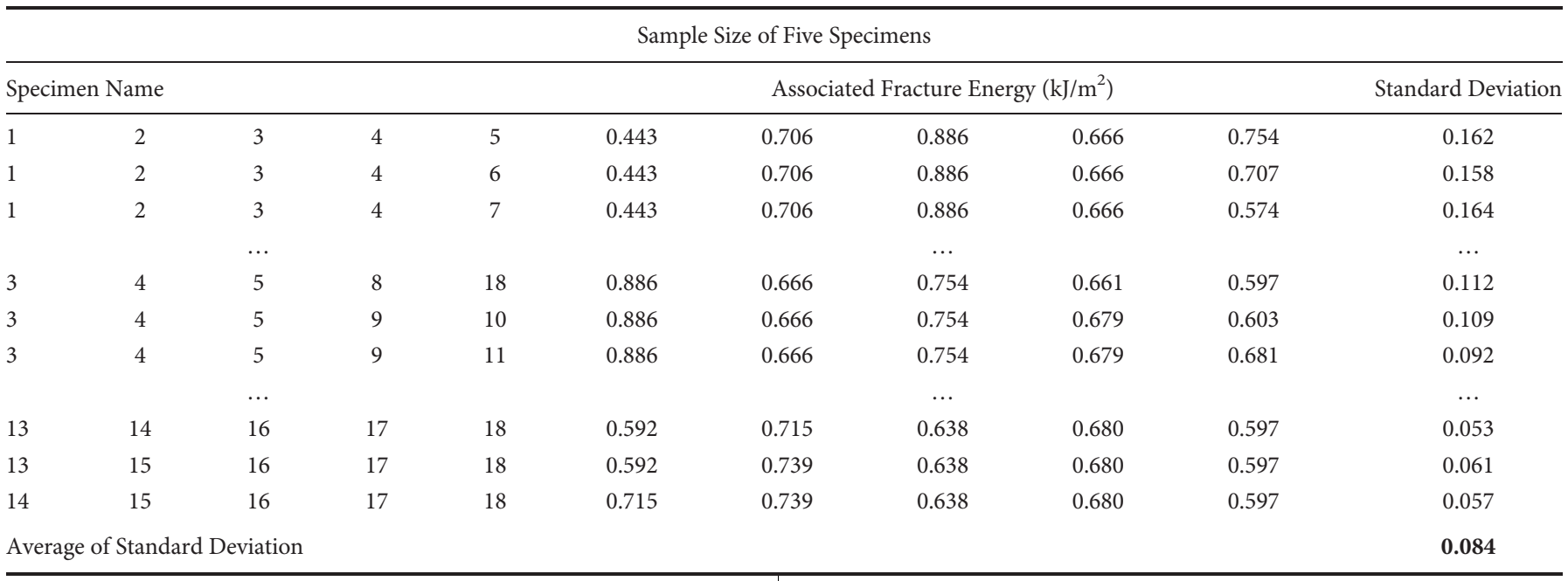

$s=$ the standard deviation of sample, and

$E=$ the margin of error expressed as:

$$
E=\bar{y}-\mu
$$

where:

$\bar{y}=$ the observed sample mean, and

$\mu=$ the true value of the population mean.

Since the true population mean $(\mu)$ is often unknown, the margin of error $(E)$ is usually introduced to achieve target accuracy.

Intrinsically, the standard deviation of sample $(s)$ depends on the sample size. Thus, in this study, to account for this dependency, different sample sizes (i.e., $k=1,2,3,4,5, \ldots$ ) were related to the standard deviation. Then, a relationship between the sample size and the minimum number of specimens was established by Eq 2. Subsequently, 18 SCB specimens were tested using typical testing variables that were reasonably selected from the literature review such as: thickness of specimen $=50 \mathrm{~mm}[31]$, notch length $=15 \mathrm{~mm}[6,30]$, loading rate $=1 \mathrm{~mm} / \mathrm{min}[5,12]$, and testing temperature $=21^{\circ} \mathrm{C}[3,9]$. Then for each sample size $(k=1,2, \ldots, 18$, in this case), the number of all possible combinations $\left(C_{k}^{p}\right)$ from the total count $(p=18$, in this case) can then be calculated by:

$$
C_{k}^{p}=\frac{p !}{k !(p-k) !} \text { where } p=18 \text { and } k=1,2,3, \ldots, 18
$$

The corresponding standard deviations for each sample size $(k)$ could then be obtained by averaging the standard deviations from the all-possible combinations $\left(C_{k}^{p}\right)$. Table 2 shows an example for sample size $(k)$ of five. Each standard deviation of fracture energy for the 8568 combinations was calculated and used to obtain the average standard deviation for $k=5$.

The results obtained from this process are presented in Fig. 6a. It is observed from the figure that there was a strong dependency of standard deviation on the sample size $(k)$ from one to approximately eight $(k=1 \sim 8)$, followed by a steady saturation thereafter. Sequentially, Eq 2 was used to calculate the minimum number of specimens $(n)$ for each sample size $(k)$.

The choice of probability level and margin of error is subjective to the accuracy desired in a test. In this study, the typical probability level of $5 \%$ (i.e., $t_{\alpha / 2, d f}=2.110$ ) was chosen, while the margin of error was taken as $10 \%$ of the average of the 18

\section{FIG. 6}

Sample size ( $k$ ) associated with: (a): standard deviation of fracture energy and (b) minimum number of specimens (n).

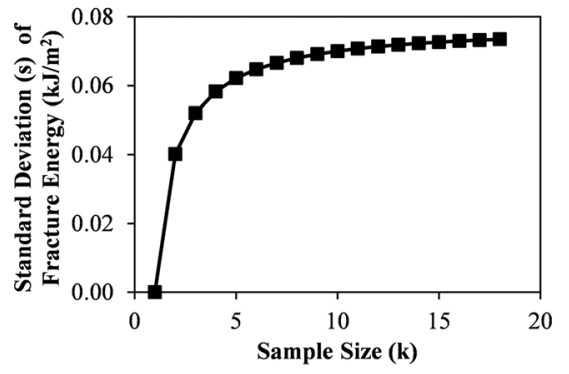

(a)

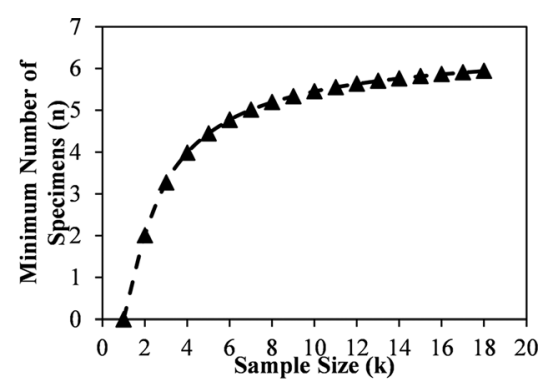

(b) 
FIG. 7

Effect of the thickness of specimens ( $t$ ): (a) test results (average of six replicates) and (b) fracture energy with $95 \%$ Confidence Interval and COV of fracture energy for different thicknesses.

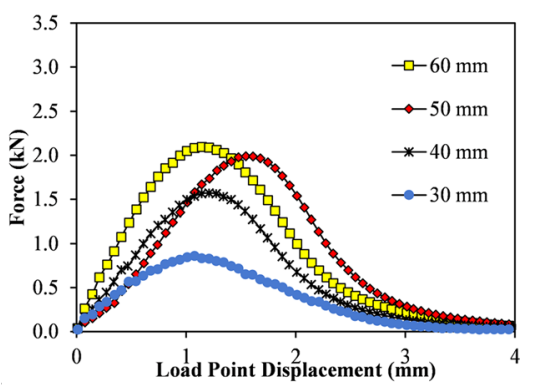

(a)

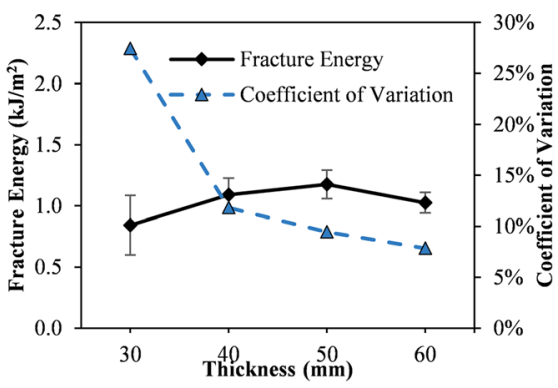

(b) specimens (i.e., $E=0.075 \mathrm{~kJ} / \mathrm{m}^{2}$ ). The results of the conversion from standard deviation to the number of specimens are presented in Fig. 6b. It shows that the minimum number of specimens increased with increasing sample size, and then tended to saturate at around six. The statistical analysis of a total of 18 SCB specimens conducted in this study infers that six SCB specimens would be a reasonable sample size that can reasonably represent the asphalt concrete fracture behavior of the entire replicates (18 specimens in this case) with a $95 \%$ confidence level.

\section{SPECIMEN THICKNESS $(t)$}

Although previous studies [31-33] highlighted that the thickness of specimens strongly affected fracture energy $\left(G_{f}\right)$, less emphasis was placed on the effect of the thickness on testing repeatability. In this study, the fracture energy and variability in the test results for various thicknesses of specimens were investigated. The thicknesses varied from $30,40,50$, to $60 \mathrm{~mm}$, and the number of specimens was fixed to six as recommended by the analysis mentioned above. Other testing variables were reasonably selected based on literature reviews: notch length $=15 \mathrm{~mm}[6,30]$, loading rate $=1 \mathrm{~mm} / \mathrm{min}[5,12]$, and testing temperature $=21^{\circ} \mathrm{C}[3,9]$. Fig. 7a clearly shows that the peak force increased as specimens became thicker, as expected. Additionally, the fracture energy increased from 30 to $50 \mathrm{~mm}$, followed by a slight decrease at a thickness of $60 \mathrm{~mm}$ (see Fig. 7b). However, the fracture energy did not seem to be significantly dependent on the thickness of specimens within the thickness range tested. It is noteworthy that the test results, in all cases, are an average of the six replicates.

To evaluate the consistency of the testing results, the coefficient of variation (COV) of the fracture energy of each thickness was estimated. Fig. 7b indicates a general decrease in COV with increasing thickness, while a steep decline between 30 and $40 \mathrm{~mm}$ was observed. This figure implies that a SCB specimen thicker than $40 \sim 50 \mathrm{~mm}$ is appropriate for characterizing the fracture behavior of asphalt concrete without significantly increasing the variability of results when other testing variables are maintained. This finding agrees well with previous studies [34], indicating that the thickness of asphalt concrete samples should be at least four times larger (i.e., $12.5 \mathrm{~mm} * 4=50 \mathrm{~mm}$ ) than nominal maximum aggregate size (NMAS), $12.5 \mathrm{~mm}$ in this study.

The high COV of the specimens with $30 \mathrm{~mm}$ thickness might be explained by an insufficient ligament area ( 30 by $60 \mathrm{~mm}$ ), which seems smaller than the typical size of a representative volume element (RVE). It is noted that a RVE is the smallest size of a region that should be tested in order to avoid a certain localized phenomenon and to provide a representative global response [35,36]. Determination of the RVE size of a specimen is beyond the scope of this study. However, it can be noted from several previous studies that the RVE size of typical asphalt concrete mixtures with a NMAS of $12.5 \mathrm{~mm}$ is around $60 \mathrm{~mm}$ by $60 \mathrm{~mm}$ [35-37], while mixtures with greater NMAS should require a larger RVE size, typically, four times NMAS [38]. For the subsequent steps, $50 \mathrm{~mm}$ was chosen based on other studies and the low $\operatorname{COV}(\leq 10 \%)$ value found in this study.

\section{NOTCH LENGTH (c)}

To investigate the effect of notch length, specimens with five notch lengths $(0,5,15,25$, and $40 \mathrm{~mm})$ were tested. Other testing variables were fixed: the number of specimens $=6$, specimen thickness $=50 \mathrm{~mm}$, loading rate $=1 \mathrm{~mm} / \mathrm{min}[5,12]$, and testing temperature $=21^{\circ} \mathrm{C}[3,9]$. Fig. 8a shows that the peak force and initial stiffness increased as notch length decreased. This trend is reasonable because specimens with smaller notch lengths have greater areas to be fractured, requiring more energy to fracture them. Another interesting observation from the figure is that the displacement at the peak force increases (i.e., shifts to the right) with decreasing notch length.

Fig. 8b shows a decreasing trend of fracture energy along with increasing notch length. The fracture energy drops from around $2 \mathrm{~kJ} / \mathrm{m}^{2}$ in the case of the notchless specimens (i.e., $0 \mathrm{~mm}$ notch length) to around $0.5 \mathrm{~kJ} / \mathrm{m}^{2}$ for the specimens with $40 \mathrm{~mm}$ notch length. The figure also presents the COV of 
FIG. 8

Effect of notch length (c): (a) test results (average of six replicates) and (b) fracture energy with $95 \%$ Confidence Interval and COV of fracture energy for different notch lengths.

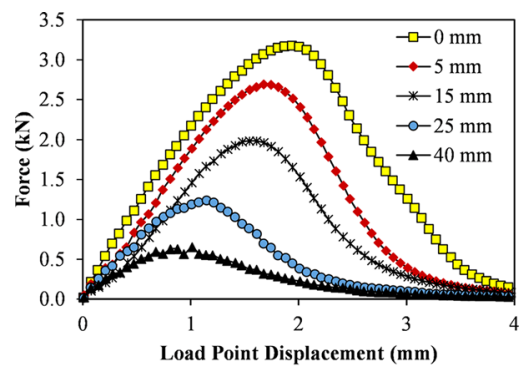

(a)

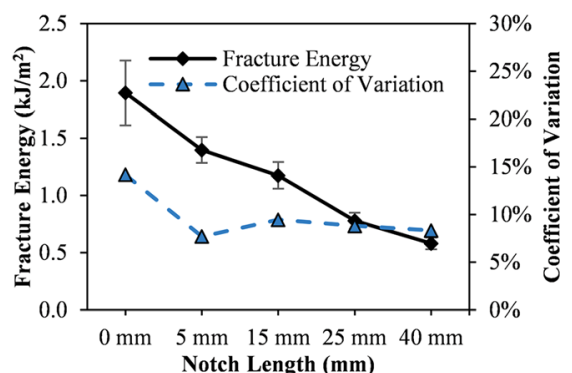

(b) fracture energy at various notch lengths. Due to the more random crack initiation/propagation, notchless specimens showed a higher COV than other specimens with a notch. In addition, from this figure, it can be seen that a COV value of less than $10 \%$ can be achieved from specimens with notch lengths between 5 and $40 \mathrm{~mm}$. Although a $5 \mathrm{~mm}$ notch case presented the lowest COV within the range of notch lengths investigated here, the resulting crack propagation was found to deviate highly from the centerline of the specimen, and thus not considered as fracture dominated by opening mode. Consequently, the $15 \mathrm{~mm}$ notch length was chosen to be used in the next steps due to the relatively better cracking propagation profile, the repeatability of the test results, and greater ligament area.

\section{LOADING RATE (LR)}

The loading rate (LR) has strong effects on the fracture behavior of asphalt concrete mixtures under intermediate temperature conditions because of the viscoelastic deformation characteristics of asphaltic materials, as demonstrated by many studies including Kim et al. [3,9]. In this study, SCB specimens were tested at five different loading rates (i.e., 0.1, 0.5, 1.0, 5.0, and $10 \mathrm{~mm} / \mathrm{min}$.), while other testing variables remained constant (i.e., the number of testing specimens $=6$, thickness of a specimen $=50 \mathrm{~mm}$, notch length $=15 \mathrm{~mm}$, and testing temperature $\left.=21^{\circ} \mathrm{C}[3,9]\right)$. As shown in Fig. 9a, the experimental results indicated that asphalt concrete mixtures at slower loading rates showed more compliant responses, whereas at faster loading rates, the mixtures exhibited stiffer responses with greater peak force. This observation generally agrees well with findings from previous studies $[3,9,12]$.

As shown in Fig. 9, both asphalt concrete forcedisplacement behavior and fracture energy were affected by the loading rate within the rage. Compared to other testing variables such as the thicknesses of specimens and notch lengths (see Fig. 7b and Fig. 8b), low COV values were observed in all cases tested with a range between 0.1 and $10 \mathrm{~mm} / \mathrm{min}$. If one selects a threshold COV of $15 \%$ for instance, any loading rate within the range can be chosen for the SCB test. Although slower loading rates showed little lesser variations, it is noted that at these rates the testing time is considerably increased without a significant improvement in testing repeatability. Thus, for the next step (i.e., investigation of testing temperature), a loading rate of $5 \mathrm{~mm} / \mathrm{min}$ was selected due to practical reasons; it was much faster than other slower cases with sufficiently good testing repeatability.

\section{TESTING TEMPERATURE ( $T$ )}

It is widely documented that asphalt concrete mixture is highly temperature-dependent due to the viscoelastic nature of asphalt binder $[12,28]$. Based on this, the next effort was to characterize the temperature effect on the repeatability of the test results, particularly for characterizing the fatigue-type cracking
FIG. 9

Effect of loading rate: (a) test results (average of six replicates) and (b) fracture energy with $95 \%$ Confidence Interval and COV of fracture energy for different loading rates.

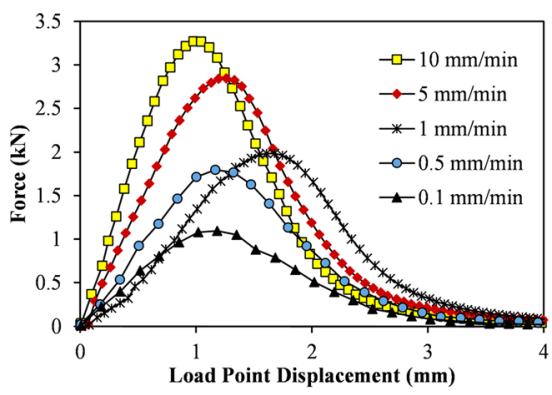

(a)

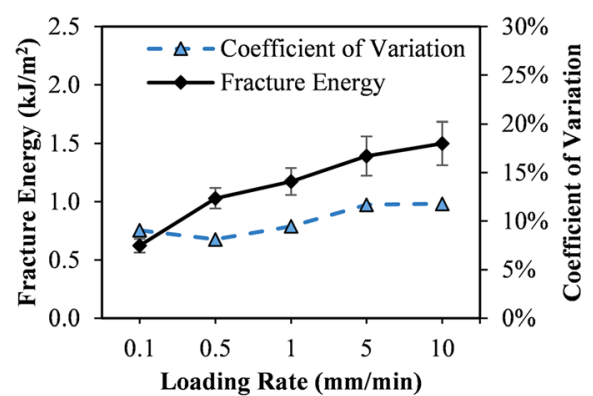

(b) 
FIG. 10

Effect of temperature: (a) test results (average of six replicates) and (b) fracture energy with $95 \%$ Confidence Interval and COV for different testing temperatures.

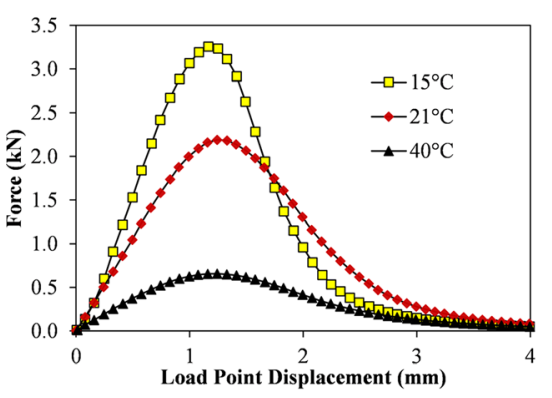

(a)

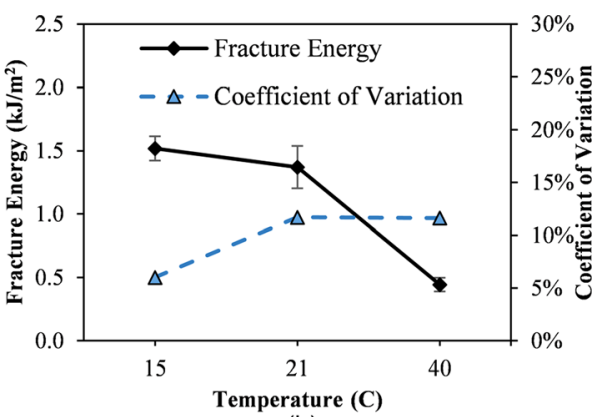

(b) potential of mixtures. As shown in Fig. 10, three different temperatures $\left(15,21\right.$, and $\left.40^{\circ} \mathrm{C}\right)$ were attempted to investigate their effects on the fracture energy. Other testing variables were maintained: the number of specimens $=6$, thickness of a specimen $=50 \mathrm{~mm}$, notch length $=15 \mathrm{~mm}$, and the loading rate $=5 \mathrm{~mm} / \mathrm{min}$. Fig. 10a clearly shows that peak force and fracture energy were inversely proportional to testing temperature.

Fig. 10b presents the COV of fracture energy at different temperatures. As shown, lower temperatures presented smaller testing variations, such that the variation of fracture energy at $15^{\circ} \mathrm{C}$ was less than the others; this is the only case with a COV value of less than $10 \%$ in this study. Nonetheless, it can be noted that SCB testing at $21^{\circ} \mathrm{C}$ could be quite attractive, with only a little loss of testing repeatability, when one considers practical applications of the SCB test method for engineering purposes. This is because $21^{\circ} \mathrm{C}$ is approximately a room temperature that is easily achievable without a sophisticated environmental chamber for testing equipment. In addition, $21^{\circ} \mathrm{C}$ seems a reasonable temperature that can properly represent fatigue-type cracking events.

\section{SUMMARY OF TEST RESULTS}

The summary of all investigated variables and their associated COV values are presented in Table 3. A range of a specimen thickness from 40 to $60 \mathrm{~mm}$, a notch length from 5 to $40 \mathrm{~mm}$, and a testing temperature between 15 and $40^{\circ} \mathrm{C}$ showed reasonably low COV values of fracture energy at around or less than $10 \%$. The loading rates $(0.1$ to $10 \mathrm{~mm} / \mathrm{min})$ attempted in this study did not show any significant differences in the COV value.

\section{Summary and Conclusions}

With an integrated experimental-statistical approach, this study investigated several SCB testing variables (i.e., the recommended minimum number of specimens, thickness of

TABLE 3 Summary of coefficients of variation from all the cases investigated in this study.

\begin{tabular}{lcccc}
\hline Thickness $(\mathrm{mm})$ & Notch Length $(\mathrm{mm})$ & Loading Rate $(\mathrm{mm} / \mathrm{min})$ & Testing Temperature $\left({ }^{\circ} \mathrm{C}\right)$ & Coefficient of Variation \\
\hline 30 & 15 & 1 & 21 & 21 \\
40 & 15 & 1 & 21 & $11.82 \%$ \\
50 & 15 & 1 & 21 & $9.46 \%$ \\
60 & 15 & 1 & 21 & $7.85 \%$ \\
50 & 0 & 1 & 21 & $14.18 \%$ \\
50 & 5 & 1 & 21 & $7.70 \%$ \\
50 & 15 & 1 & 21 & $9.46 \%$ \\
50 & 25 & 1 & 21 & $8.81 \%$ \\
50 & 40 & 1 & 21 & $8.33 \%$ \\
50 & 15 & 0.1 & 21 & $9.05 \%$ \\
50 & 15 & 0.5 & 21 & $8.12 \%$ \\
50 & 15 & 1 & 21 & $9.46 \%$ \\
50 & 15 & 5 & 21 & $11.70 \%$ \\
50 & 15 & 10 & 15 & $11.79 \%$ \\
50 & 15 & 5 & 21 & $6.02 \%$ \\
50 & 15 & 5 & 40 & $11.70 \%$ \\
\hline
\end{tabular}


specimens, notch length, loading rate, and testing temperature) that are considered to have a significant effect on the overall fracture behavior of asphalt concrete mixtures at intermediate service temperature conditions. In order to pursue a reliable and repeatable SCB test for asphalt concrete fracture characterization, each testing variable of the five was investigated in turn with a typical range to estimate testing repeatability. Based on the test-analysis results, the following conclusions can be drawn:

- The statistical analysis of a total of 18 SCB specimens indicated that approximately six SCB specimens would be a reasonable sample size that can sufficiently represent asphalt concrete fracture behavior with a $95 \%$ level of confidence.

- A range of 40 to $60 \mathrm{~mm}$ for the specimen thickness showed good repeatability $(\mathrm{COV} \leq 10 \%)$ and similar consistent fracture energies, while the test results with $30 \mathrm{~mm}$ SCB thickness showed a high COV (>25\%).

- Within the range tested in this study, notches from 5 to $40 \mathrm{~mm}$ displayed a relatively low variability $(\mathrm{COV} \leq 10 \%)$ of fracture energy, while the testing results without a notch showed high variability $(\mathrm{COV} \approx 15 \%)$.

- Fracture energy showed dependency on loading rate within the ranges investigated in this study. However, the loading rates $(0.1$ to $10 \mathrm{~mm} / \mathrm{min}$ ) attempted in this study did not show any significant differences in the COV value.

- In the range of testing temperatures attempted here, fracture energy at around $15^{\circ} \mathrm{C}$ showed the lowest testing variation. SCB testing at $21^{\circ} \mathrm{C}$ also seems attractive for practical application, with a little loss of testing repeatability compared to $15^{\circ} \mathrm{C}$, because $21^{\circ} \mathrm{C}$ is a room temperature that is easily achievable with little environmental control for testing.

- The findings of this study are under further evaluation for various Nebraska asphalt concrete mixtures that are placed in field projects. This will lead to closer insights into the SCB fracture through a potential quality control (QC)-quality assurance (QA) type approach to evaluate the fatigue cracking potential of asphalt concrete mixtures. Any further findings will be reported in follow-up studies.

\section{ACKNOWLEDGMENTS}

The writers gratefully acknowledge the financial support received from the Nebraska Department of Roads (NDOR) for this study.

\section{References}

[1] Wagoner, M. P., Buttlar, W. G., Paulino, G. H., and Blankenship, P., "Investigation of the Fracture Resistance of Hot-Mix Asphalt Concrete Using a Disk-Shaped Compact Tension Test," Transp. Res. Rec., Vol. 1929, 2005, pp. 183-192.
[2] Marasteanu, M. O., Dai, S., Labuz, J. F., and Li, X., "Determining the Low-Temperature Fracture Toughness of Asphalt Mixtures," Transp. Res. Rec., Vol. 1789, 2002, pp. 191-199.

[3] Im, S., Ban, H., and Kim, Y.-R., "Characterization of Mode-I and Mode-II Fracture Properties of Fine Aggregate Matrix Using a Semicircular Specimen Geometry," Constr. Build. Mater., Vol. 52, 2014, pp. 413-421.

[4] Aragão, F. T. S. and Kim, Y. R., "Mode I Fracture Characterization of Bituminous Paving Mixtures at Intermediate Service Temperatures," Exp. Mech., Vol. 52, No. 9, 2012, pp. 1423-1434.

[5] Biligiri, K. P., Said, S., and Hakim, H., “Asphalt Mixtures' Crack Propagation Assessment Using Semi-Circular Bending Tests," Int. J. Pave. Res. Technol., Vol. 5, No. 4, 2012, pp. 209-217.

[6] Li, X. J. and Marasteanu, M. O., "Using Semi Circular Bending Test to Evaluate Low Temperature Fracture Resistance for Asphalt Concrete," Exp. Mech., Vol. 50, No. 7, 2009, pp. 867-876.

[7] Shu, X., Huang, B., and Vukosavljevic, D., "Evaluation of Cracking Resistance of Recycled Asphalt Mixture Using Semi-Circular Bending Test," presented at the GeoShanghai International Conference 2010, Shanghai, China, June 3-5, 2010, ASCE, Reston, VA, pp. 58-65.

[8] Saadeh, S., Hakimelahi, H., and Harvey, J., "Correlation of Semi-Circular Bending and Beam Fatigue Fracture Properties of Asphalt Concrete Using Non-Contact Camera and Crosshead Movement," presented at the T\&DI Congress 2014@sPlanes, Trains, and Automobiles, Orlando, FL, June 8-11, 2014, ASCE, Reston, VA, pp. 39-48.

[9] Kim, Y.-R. and Aragão, F. T. S., "Microstructure Modeling of Rate-Dependent Fracture Behavior in Bituminous Paving Mixtures," Finite Elements Anal. Des., Vol. 63, 2013, pp. 23-32.

[10] Liu, J. H., "Fatigue Life Evaluation of Asphalt Rubber Mixtures Using Semi-Circular Bending Test," Adv. Mater. Res., Vols. 255-260, 2011, pp. 3444-3449.

[11] Zegeye, E., Le, J.-L., Turos, M., and Marasteanu, M., "Investigation of Size Effect in Asphalt Mixture Fracture Testing at Low Temperature," Road Mater. Pave. Des., Vol. 13, 2012, pp. 88-101.

[12] Im, S., Kim, Y.-R., and Ban, H., "Rate-and TemperatureDependent Fracture Characteristics of Asphaltic Paving Mixtures," J. Test. Eval., Vol. 41, No. 2, 2013, pp. 257-268.

[13] Wu, Z., Mohammad, L. N., Wang, L., and Mull, M. A., "Fracture Resistance Characterization of Superpave Mixtures Using the Semi-Circular Bending Test," J. ASTM Int., Vol. 2, No. 3, 2005, pp. 1-15.

[14] Im, S., Ban, H., and Kim, Y.-R., "Mode-Dependent Fracture Behavior of Asphalt Mixtures With Semicircular Bend Test," Transp. Res. Rec., Vol. 2447, 2014, pp. 23-31.

[15] Chong, K. and Kuruppu, M., "New Specimen for Fracture Toughness Determination for Rock and Other Materials," Int. J. Fract., Vol. 26, No. 2, 1984, pp. R59-R62.

[16] Huang, B., Shu, X., and Zuo, G., "Using Notched Semi Circular Bending Fatigue Test to Characterize Fracture Resistance of Asphalt Mixtures," Eng. Fract. Mech., Vol. 109, 2013, pp. 78-88.

[17] Li, X. and Marasteanu, M. O., "Investigation of Low Temperature Cracking in Asphalt Mixtures by Acoustic 
Emission," Road Mater. Pave. Des., Vol. 7, No. 4, 2006, pp. 491-512.

[18] Li, X., Braham, A. F., Marasteanu, M. O., Buttlar, W. G., and Williams, R. C., "Effect of Factors Affecting Fracture Energy of Asphalt Concrete at Low Temperature," Road Mater. Pave. Des., Vol. 9, 2008, pp. 397-416.

[19] Leng, Z., Gamez, A., and Al-Qadi, I. L., "Mechanical Property Characterization of Warm-Mix Asphalt Prepared With Chemical Additives," J. Mater. Civ. Eng., Vol. 26, No. 2, 2013, pp. 304-311.

[20] Al-Qadi, I. L., Aurangzeb, Q., Carpenter, S. H., Pine, W. J., and Trepanier, J., "Impact of High RAP Contents on Structural and Performance Properties of Asphalt Mixtures," Report No. FHWA-ICT-12-002, FHWA, Washington, D.C., 2012.

[21] Al-Qadi, I. L., Ozer, H., Lambros, J., El Khatib, A., Singhvi, P., Khan, T., Rivera-Perez, J., and Doll, B., "Testing Protocols to Ensure Performance of High Asphalt Binder Replacement Mixes Using RAP and RAS," Report No. 0197-9191, Illinois Center for Transportation/Illinois Department of Transportation, Rantoul, IL, 2015.

[22] Elseifi, M. A., Mohammad, L. N., Ying, H., and Cooper III, S., "Modeling and Evaluation of the Cracking Resistance of Asphalt Mixtures Using the Semi-Circular Bending Test at Intermediate Temperatures," Road Mater. Pave. Des., Vol. 13, 2012, pp. 124-139.

[23] Allen, D. H., Lutif, J. E. S., and Kim, Y.-R., "Determining Representative Volume Elements of Asphalt Concrete Mixtures Without Damage," Transp. Res. Rec., Vol. 2127, 2009, pp. 52-59.

[24] Faruk, A. N., Hu, X., Lopez, Y., and Walubita, L. F., "Using the Fracture Energy Index Concept to Characterize the HMA Cracking Resistance Potential Under Monotonic Crack Testing," Int. J. Pave. Res. Technol., Vol. 7, 2014, pp. $40-48$.

[25] Mull, M., Stuart, K., and Yehia, A., "Fracture Resistance Characterization of Chemically Modified Crumb Rubber Asphalt Pavement," J. Mater. Sci., Vol. 37, No. 3, 2002, pp. 557-566.

[26] Dowdy, S., Wearden, S., and Chilko, D., Statistics for Research, John Wiley \& Sons, New York, 2011.

[27] Mohammad, L. N., Kim, M., and Elseifi, M., "Characterization of Asphalt Mixture's Fracture Resistance
Using the Semi-Circular Bending (SCB) Test," presented at the 7th RILEM International Conference on Cracking in Pavements, Delft, the Netherlands, June 20-22, 2012, Springer, New York, pp. 1-10.

[28] Marasteanu, M. O., Li, X., Clyne, T. R., Voller, V., Timm, D. H., and Newcomb, D., "Low Temperature Cracking of Asphalt Concrete Pavement," Final Report, 2004-23, Minnesota Department of Transportation, St. Paul, MN, 2004.

[29] RILEM Recommendation, "Determination of the Fracture Energy of Mortar and Concrete by Means of Three-Point Bend Tests on Notched Beams," Mater. Struct., Vol. 18, No. 6, 1985, pp. 484-484.

[30] EN 12697-44, Crack Propagation by Semi-Circular Bending Test, Bituminous Mixtures-Test Methods for Hot Mix Asphalt, Publisher, Brussels, Belgium, 2010.

[31] Duan, K., Hu, X.-Z., and Wittmann, F. H., "Thickness Effect on Fracture Energy of Cementitious Materials," Cem. Concr. Res., Vol. 33, No. 4, 2003, pp. 499-507.

[32] Brühwiler, E., Wang, J., and Wittmann, F., "Fracture of AAC as Influenced by Specimen Dimension and Moisture," J. Mater. Civ. Eng., Vol. 2, No. 3, 1990, pp. 136-146.

[33] Hu, X. and Duan, K., "Influence of Fracture Process Zone Height on Fracture Energy of Concrete," Cem. Concr. Res., Vol. 34, No. 8, 2004, pp. 1321-1330.

[34] Wittmann, X. and Zhong, H., On Some Experiments to Study the Influence of Size on Strength and Fracture Energy of Concrete, Aedificatio Verlag, Breisgau, Germany, 1996.

[35] Kim, Y.-R., Lutif, J., and Allen, D., "Determining Representative Volume Elements of Asphalt Concrete Mixtures Without Damage," Transp. Res. Rec., Vol. 2127, 2009, pp. 52-59.

[36] Romero, P. and Masad, E., "Relationship Between the Representative Volume Element and Mechanical Properties of Asphalt Concrete," J. Mater. Civ. Eng., Vol. 13, No. 1, 2001, pp. 77-84.

[37] Kim, Y., Lee, J., and Lutif, J. E., "Geometrical Evaluation and Experimental Verification to Determine Representative Volume Elements of Heterogeneous Asphalt Mixtures," J. Test. Eval., Vol. 38, No. 6, 2010, pp. 660-666.

[38] Wagnoner, M., Buttlar, W., and Paulino, G., "Disk-Shaped Compact Tension Test for Asphalt Concrete Fracture," Exp. Mech., Vol. 45, No. 3, 2005, pp. 270-277. 